Research Article

\title{
Study on the Attenuation Characteristics of Seismic Wave Energy Induced by Underwater Drilling and Blasting
}

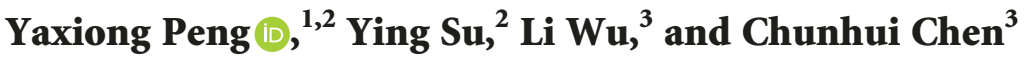 \\ ${ }^{1}$ Hunan Provincial Key Laboratory of Geotechnical Engineering for Stability Control and Health Monitoring, \\ Hunan University of Science and Technology, Xiangtan 411201, China \\ ${ }^{2}$ School of Civil Engineering, Hunan University of Science and Technology, Xiangtan, Hunan, China \\ ${ }^{3}$ Faculty of Engineering, China University of Geosciences, Wuhan, China \\ Correspondence should be addressed to Yaxiong Peng; 1020172@hnust.edu.cn
}

Received 19 June 2019; Revised 14 August 2019; Accepted 4 September 2019; Published 26 September 2019

Academic Editor: Marcello Vanali

Copyright (c) 2019 Yaxiong Peng et al. This is an open access article distributed under the Creative Commons Attribution License, which permits unrestricted use, distribution, and reproduction in any medium, provided the original work is properly cited.

\begin{abstract}
Seismic wave induced by underwater drilling and blasting may exert adverse effects to the surrounding structures. Peak particle velocity (PPV) has been widely used to reflect the intensity of seismic wave, while the method fails to take other influential parameters into consideration. Synthesizing PPV and duration, seismic wave energy (SWE) is employed to quantify the intensity, and the method of time-frequency analysis is adopted to study the characteristics of vibration frequency. Besides, this paper deduces the prediction formula for SWE via dimension analysis. Based on the practical engineering, the attenuation characteristics of SWE induced by underwater drilling and blasting is analysed by the wavelet transform and adaptive optimal kernel (AOK) time-frequency analysis method. Results show that the dominant frequencies at the directions of horizontal tangential, horizontal radial, and vertical are different and the energies in high-frequency bands are extremely low. Moreover, the lower the frequency is, the slower the attenuation of SWE is. Comparing with other prediction formulas of PPV, fitting the SWE with the help of the prediction formula in this study would achieve more accurate prediction results.
\end{abstract}

\section{Introduction}

Underwater drilling and blasting has become an important rock excavation method in construction projects such as harbours, wharfs, and channels. With the development of waterway transport, such projects have increased sharply and projects with large rock mass volume and large explosive charge have been the trend. In underwater blasting engineering, only $20 \%$ to $30 \%$ energy released by explosive explosion is spent to break rock mass, while the rest exerts adverse effects to the surrounding environment, such as seismic wave, shock wave, dust and fumes, and fly rocks. [1-3]. Among which, seismic wave is the most destructive one. That is to say, the most effective method to reduce the adverse effects is to control the intensity of seismic waves.

Three key elements of seismic wave include peak particle velocity (PPV), frequency, and duration. PPV is frequently employed to quantify the intensity of seismic wave, and the value is deemed to be influenced by the quantity of explosive charge, the distance from the measured point to the blastface, and the geological conditions of the excavation area. In a certain site, the geological conditions and the distance from the measured point to the blast-face are uniquely determined. Thus, field tests are applied to predict PPV and the quantity of explosive charges are adjusted to lower the value to the safe range. Through numbers of experiments, the prediction formulas of PPV have been derived by numerous scholars [4-7]. And, the elevation difference factor $\beta$ was introduced to modify the prediction formula $[8,9]$. The vibration attenuation law and elevation effect of underwater drilling and blasting were studied by nonlinear regression and robust regression $[10,11]$. Gu et al. $[12,13]$ deduced a revised formula for water depth and obtained PPVs in water bottom and shore. In order to improve the prediction accuracy, the genetic algorithm has been widely used to fit PPV [13-15]. Khandelwal and Singh [16-18] applied various 
artificial neural networks to predict PPV, and all achieved good results. Liu et al. [19] studied PPV induced by underwater blasting based on the combination of grey relational analysis and genetic neural network.

When the seismic wave frequency is close to the structure natural frequency, the structure may be damaged by resonance. Due to the continuous blasting vibration, the allowable vibration velocity of the structure may decrease dramatically. Therefore, the frequency and duration of seismic waves also have large influence on the nearby structure. The research team of Professor Lu studied the distribution characteristics and attenuation law of blasting frequency under different engineering conditions [20,21]. Zhong et al. [22] discussed the influential parameters of duration and established the prediction formula with the help of dimensional analysis. In terms of underwater blasting engineering, Peng et al. [23] deduced the functional relationship among the vibration frequency and other relevant influential parameters. Lia et al. [24] proposed a novel model for predicting PPV, which embodied the effects of geological factor, rock properties, and engineering category.

The above researches are based on the single factor for the intensity of seismic waves, which fail to take all the factors into consideration. Thus, numerous scholars have studied the seismic waves from the aspect of seismic wave energy (SWE). Sanchidrián et al. [25] divided the elements of explosive energy into 3 parts, the fragmentation energy, the seismic energy, and the kinetic energy, and deduced the corresponding calculation formulas, respectively. Li et al. [26] studied the distribution characteristics of SWE under different forms of blasting and obtained the prediction formula of energy attenuation. Ling and Li [27] and Yang et al. [28] studied the distribution characteristics and the safety control method of SWE with the help of wavelet transform and time-frequency analyses. Researches above indicate that the parameter of SWE can perfectly reflect the characteristics of seismic wave.

Above researches are mainly based on land blasting, while underwater drilling and blasting is quite different from land blasting due to the presence of water media. Thus, the paper deduces the attenuation formula for the total energy of seismic wave based on the signal analysis of particle energy. Many field measured data are collected, and the distribution characteristics and attenuation law of SWE in different frequency bands are studied with the help of wavelet transform and AOK time-frequency analysis. Furthermore, the attenuation formula is adopted to predict the SWE in practical engineering.

\section{Theoretical Study}

2.1. Prediction Formula of $P P V$. It has been the consensus that the particle vibration velocity can be employed to describe the intensity of seismic wave. By analysing a large number of measured data, researchers deduced various prediction formulas of PPV, part of which is shown in Table 1 [4-7]. In underwater drilling and blasting engineering, monitoring points can only be set on the riverbank slope. Under the circumstance of deep water depth,
TABle 1: Different vibration prediction formulas $[4-7,9]$.

\begin{tabular}{lc}
\hline Prediction formula & Equation \\
\hline USBM & $v=k(R / \sqrt{Q})^{-\alpha}$ \\
Langefors-Kihlstrom & $v=k\left(\sqrt{Q / R^{2 / 3}}\right)^{\alpha}$ \\
Bureau of Indian Standard & $v=k\left(Q / R^{2 / 3}\right)^{\alpha}$ \\
Sadaovsk formula & $v=k\left(Q^{1 / 3} / R\right)^{\alpha}$ \\
CCTS & $v=k\left(Q^{1 / 3} / R\right)^{\alpha}\left(Q^{1 / 3} /|H|\right)^{\beta}$ \\
\hline
\end{tabular}

the influence that the elevation difference has on the propagation of seismic wave will also increase substantially. Chinese Construction Technical Specifications (CCTS) [9] proposed a prediction formula of PPV involving the effects of elevation, which is shown in Table 1. In the table, $Q$ is the maximal charge per delay, $R$ is the distance from the measured point to the blast-face, $H$ is the altitude from the measured point to the blast-face, and $k, \alpha$, and $\beta$ are the parameters related to the transmission medium.

2.2. Prediction Formula of SWE. When studying the influence that blasting seismic waves exert on the surrounding environment, the kinetic energy is the primary factor to be concerned. At time $t$, the SWE for an elementary mass $\Delta m$ in space can be expressed as follows:

$$
e(t)=\frac{1}{2} \Delta m \cdot v^{2}(t)
$$

where $e(t)$ is the SWE at time $t, \Delta m$ is the elementary mass, and $v(t)$ is the velocity at time $t$.

To leave out the effect of point mass, the SWE per mass unit $e_{m}(t)$ can be deduced as follows:

$$
e_{m}(t)=\frac{e(t)}{\Delta m}=\frac{1}{2} v^{2}(t)
$$

Thus, the energy per mass unit $E$ for the entire process of blasting vibration can be calculated by

$$
E=\int_{0}^{t} e_{m}(t) d t=\frac{1}{2} \int_{0}^{t} v^{2}(t) d t
$$

Blasting seismic wave is a random signal with transient characteristics. As the formation and propagation of blasting seismic wave are affected by numerous factors, it is too hard to establish the prediction formula which takes all the factors into consideration. Thus, merely several major influential parameters are selected for studies. A dimensional analysis (DA) technique has been performed on major influential parameters to propose a new formula [29].

In general, PPV $(v)$, seismic wave energy $(E)$, seismic wave frequency $(f)$, and seismic wave duration $(t)$ are the primary parameters to describe the effect of blasting seismic wave $[13,30]$. In underwater blasting engineering, maximal charge per delay and distance from the measured point to the blast-face have remarkable influence on SWE, and geological conditions and rock properties also have major effect on it $[26,31]$. As a result, maximal charge per delay $(Q)$, distance from the measured point to the blast-face $(R)$, altitude from the measured point to the blast-face $(H)$, hole 
depth $(h)$, delay interval $\left(T_{\mathrm{d}}\right)$, density of rock mass $(\rho)$, and medium velocity of seismic waves $(c)$ are chosen as the main physical quantities. Therefore, it is generally agreed that the propagation process of seismic wave induced by underwater drilling and blasting involves 11 parameters, as shown in Table 2.

As seen from the table, totally 11 influential parameters are adopted to quantify the intensity of seismic wave induced by underwater drilling and blasting. According to the $\pi$ theorem, $Q, R$, and $c$ are selected to be the basic physical variables [13]:

$$
F\left(Q, R, c, v, E, f, t, H, h, T_{\mathrm{d}}, \rho\right)=0 .
$$

Suppose that $\pi$ is denoted as the dimensionless group, the value of $\pi$ can be solved via the following composite formula:

$$
\pi=Q^{x} R^{y} c^{z} X,
$$

where $X$ is the variable except the above basic physical variables in Table 2; $x, y$, and $z$ are undetermined coefficients.

According to the dimensionless homogeneous theorem, the variable $v$ can be calculated via the following equation:

$$
\operatorname{dim} v=\mathrm{LT}^{-1}=(\mathrm{M})^{x}(\mathrm{~L})^{y}\left(\mathrm{LT}^{-1}\right)^{z} .
$$

As $x_{1}=0, y_{1}=0$, and $z_{1}=-1$, the simplified formula is depicted as follows:

$$
\pi_{1}=c^{-1} \cdot v .
$$

For the convenience of analysis, other simplified formulas are given:

$$
\begin{aligned}
& \pi_{2}=c^{-2} \cdot E, \\
& \pi_{3}=R c^{-1} \cdot f, \\
& \pi_{4}=R^{-1} c \cdot t, \\
& \pi_{5}=Q^{1 / 3} H^{-1} \cdot \rho^{-(1 / 3)}, \\
& \pi_{6}=R^{-1} \cdot h, \\
& \pi_{7}=R^{-1} c \cdot T_{\mathrm{d}}, \\
& \pi_{8}=Q^{1 / 3} R^{-1} \cdot \rho^{-(1 / 3)} .
\end{aligned}
$$

Combining equations (4), (7), and (8), $\pi$ can be expressed as follows:

$$
\begin{aligned}
\pi= & \Phi\left(c^{-1} v, c^{-2} E, R c^{-1} f, R^{-1} c t, Q^{1 / 3} H^{-1} \rho^{-(1 / 3)},\right. \\
& \left.R^{-1} h, R^{-1} c T_{\mathrm{d}}, Q^{1 / 3} R^{-1} \rho^{-(1 / 3)}\right) .
\end{aligned}
$$

Since the product of several dimensionless values is still a dimensionless value, the equation of similar dimensionless group related to SWE can be depicted as follows:

$$
\pi_{2}=\pi_{5} \cdot \pi_{8} .
$$

According to equations (9) and (10), there is a certain functional relationship among $c^{-2} E, Q^{1 / 3} H^{-1} \rho^{-(1 / 3)}$, and $Q^{1 / 3} R^{-1} \rho^{-(1 / 3)}$. As the parameters $c$ and $\rho$ for a certain site can be treated as constants [8], the function can be expressed as follows:

$$
\ln E=k_{1}+\gamma_{1} \ln \left(\frac{\mathrm{Q}^{1 / 3}}{R}\right)-\left[k_{2}-\gamma_{2} \ln \left(\frac{\mathrm{Q}^{1 / 3}}{|H|}\right)\right] .
$$

Referring to the Sadaovsk Formula, assume that $k_{E}=-k_{1} k_{2}, \alpha_{E}=\gamma_{1}$, and $\beta_{E}=\gamma_{2}$, and the prediction formula of SWE can be derived as follows:

$$
E=-k_{1} k_{2}\left(\frac{Q^{1 / 3}}{R}\right)^{\gamma_{1}} \cdot\left(\frac{Q^{1 / 3}}{|H|}\right)^{\gamma_{2}}=k_{E}\left(\frac{Q^{1 / 3}}{R}\right)^{\alpha_{E}} \cdot\left(\frac{Q^{1 / 3}}{|H|}\right)^{\beta_{E}},
$$

where $E$ is the SWE, $\mathrm{cm}^{2} / \mathrm{s}^{2} ; k_{E}, \alpha_{E}$, and $\beta_{E}$ are the parameters related to the transmission medium.

\section{Case Study}

3.1. Project Profile. The construction project of Jiulongpo to Chaotianmen reach in the upper Yangtze River is located in the central downtown area of Chongqing, China. The length of the reach is around $22 \mathrm{~km}$. As the designed water level of the Three Gorges is up to $175 \mathrm{~m}$ and the reach is located in the upper fluctuating backwater area, the maintenance workload will increase with years and may even form new silt shoals. There are 5 reefs to be exploded in the dredging project, and the total amount of the reef is about $154,000 \mathrm{~m}^{3}$. The measured data of this research are collected from the Zuanzhaozi Reef, which is saturated with moderate and strong weathering sandstones. The length, width, and height of the reef are, respectively, $210 \mathrm{~m}, 90 \mathrm{~m}$, and $171 \mathrm{~m}$. The construction period lasts for one year. And, due to seasonal changes of the water level of the Yangtze River, the water depth of construction ranges from 8 to $14 \mathrm{~m}$. The location and the site conditions are depicted in Figure 1 .

The underwater holes were drilled with the help of a drill-burst ship. The single-row and multihole blasting was employed, and the number of holes was selected in line with the cross-sectional shapes of reefs. In order to adapt to underwater blasting environment, $2^{\#}$ emulsion explosives were adopted, and the detonation velocity was about $3500 \mathrm{~m} / \mathrm{s}$. Besides, the electric network was selected to detonate the explosives, and electric detonators with millisecond delay time were used to control the delay interval. The detailed design parameters are shown as Table 3.

3.2. Data Monitoring. The data of blasting seismic wave were collected by TC- 4850 blasting vibration meters, and the monitoring points were set on riverbank. The vibration meter has three channels and can collect seismic signals from three directions, the horizontal radial, the horizontal tangential, and the vertical direction. The received frequency is set at $4000 \mathrm{sps}$, and the sampling duration is $1 \mathrm{~s}$. 30 groups of data are collected in this study, and the distance from the measured point to the blast-face is measured by GPS. The statistics for monitoring data are shown in Table 4, and the typical signal of seismic wave is shown in Figure 2. 
TABLE 2: Major influential parameters.

\begin{tabular}{lccc}
\hline Type & Symbol & Meaning & Dimension \\
\hline & $v$ & Peak particle velocity & $\mathrm{LT}^{-1}$ \\
Dependent variables & $E$ & Seismic wave energy & $\mathrm{L}^{2} \mathrm{~T}^{-2}$ \\
& $f$ & Seismic wave frequency & $\mathrm{T}^{-1}$ \\
\hline & $Q$ & Seismic wave duration & $\mathrm{T}$ \\
Independent variables & $R$ & Maximal charge per delay & $\mathrm{L}$ \\
& $H$ & Altitude from the measured point to the blast-face & $\mathrm{L}$ \\
& $h$ & Hole depth & $\mathrm{L}$ \\
& $T_{\mathrm{d}}$ & Delay interval & $\mathrm{ML}^{-3}$ \\
& $\rho$ & Density of rock mass & $\mathrm{LT}^{-1}$ \\
\hline
\end{tabular}

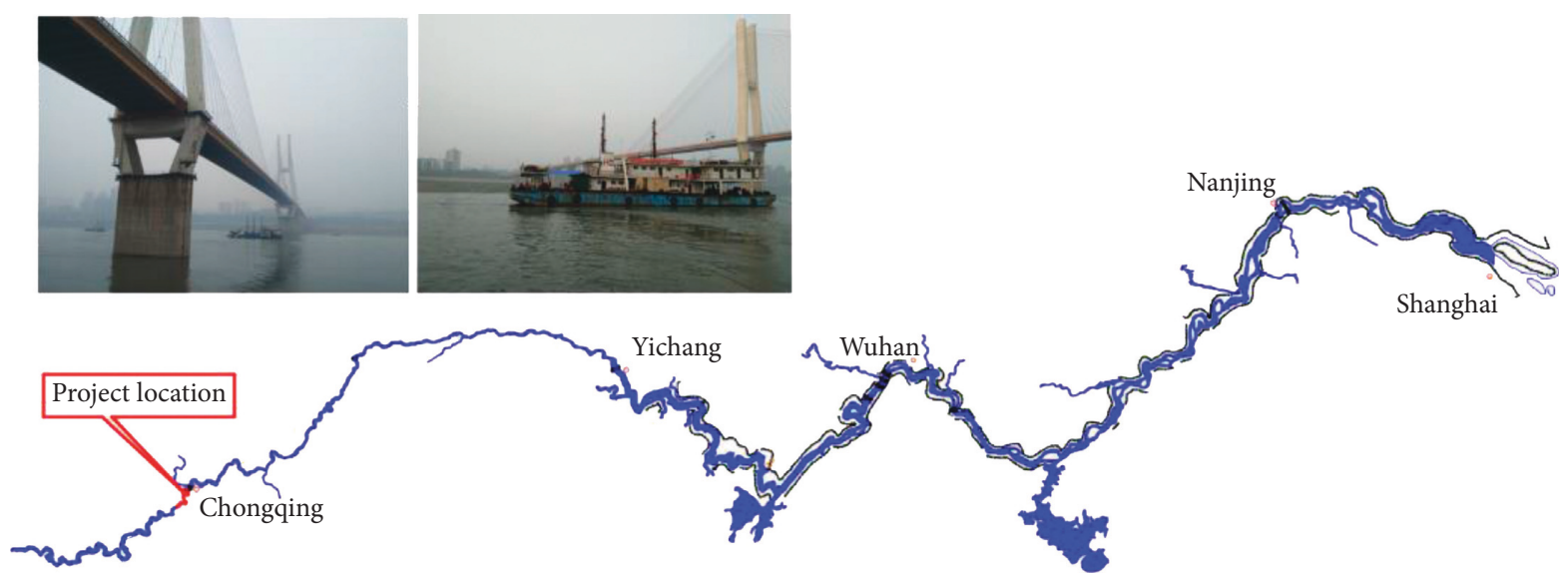

FIGURE 1: Project location and site photos.

TABle 3: Detailed blasting design parameters.

\begin{tabular}{lcccccc}
\hline Hole diameter $(\mathrm{mm})$ & Hole depth $(\mathrm{m})$ & Extra-deep $(\mathrm{m})$ & Hole space $(\mathrm{m})$ & Array pitch $(\mathrm{m})$ & Number of hole & Delay time $(\mathrm{ms})$ \\
\hline 110 & $7.2 \sim 13.7$ & 1.5 & 2 & 2.5 & $9 \sim 12$ & $25 \sim 125$ \\
\hline
\end{tabular}

TABLE 4: Statistics for monitoring data.

\begin{tabular}{|c|c|c|c|c|}
\hline Parameter & Unit & Min. & Max. & Mean \\
\hline Maximal charge per delay & $\mathrm{kg}$ & 32 & 56 & 46.4 \\
\hline Total charge & $\mathrm{kg}$ & 320 & 560 & 440 \\
\hline Distance from the blast-face to the monitoring point & $\mathrm{m}$ & 65 & 260 & 87.5 \\
\hline Altitude from the blast-face to the monitoring point & $\mathrm{m}$ & 20 & 40 & 29.2 \\
\hline Depth of blasthole & $\mathrm{m}$ & 8.6 & 14.8 & 12.2 \\
\hline Peak particle velocity & $\mathrm{cm} / \mathrm{s}$ & 0.250 & 1.963 & 1.027 \\
\hline
\end{tabular}

\section{Characteristics of SWE}

\subsection{Time-Frequency Analysis}

4.1.1. Wavelet Transform. Mallat [32] proposed the concept of multiresolution analysis when constructing orthogonal wavelet basis, illustrated the multiresolution characteristics of wavelet in geometric space, and deduced the fast algorithm for the decomposition and reconstruction of wavelet transform. The basic idea is to transform the signal $f(t)$ into two orthogonal subsignals, $a_{j} f$ and $d_{j} f$, with scale $j$. Among which, $a_{j} f$, the approximation signal, is corresponding to the low-frequency component, while $d_{j} f$, the detail signal, is for the high one. Next, transform the subsignal $a_{j} f$ into signals $a_{j+1} f$ and $d_{j+1} f$ with scale $j+1$. Thus, the signal is decomposed and reconstructed with multiresolution and multiscale analysis. The decomposition and reconstruction of wavelet with scale 3 are shown in Figure 3.

4.1.2. AOK Time-Frequency Analysis. Baraniuk and Jones [33] proposed the idea of adaptive optimal kernel (AOK) 


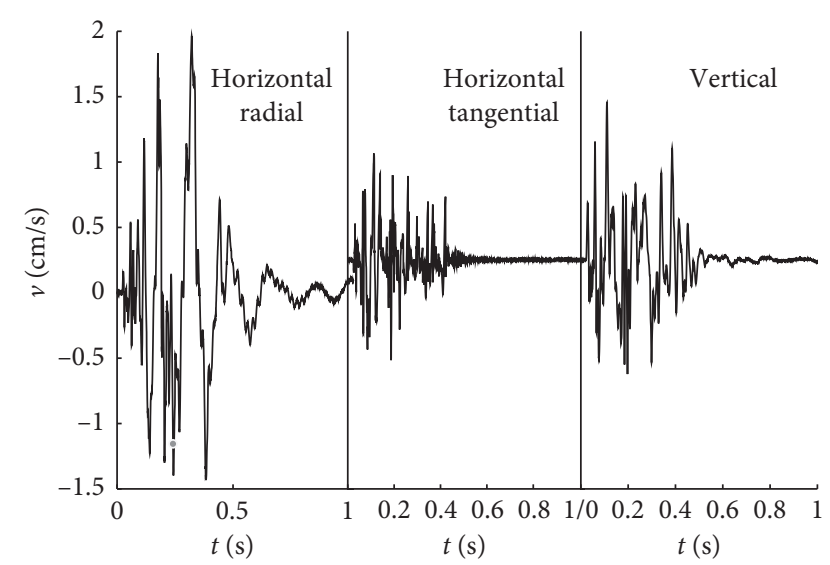

Figure 2: Typical signal of seismic wave.

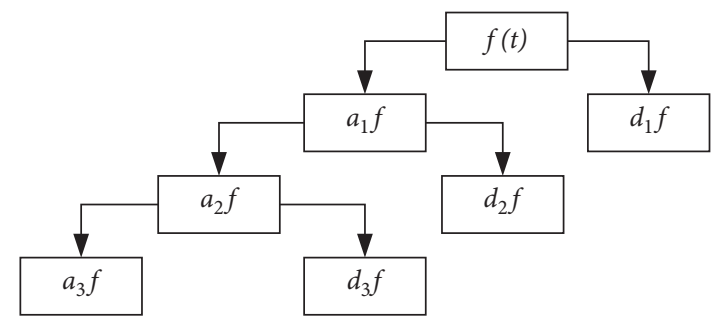

FIGURE 3: Decomposition and reconstruction of wavelet with scale 3.

time-frequency analysis. The main idea is to select appropriate short-time ambiguity function and adaptive timevarying kernel function. Thus, more details of subsignals can be expressed. AOK time-frequency distribution is defined as follows:

$$
P(t, f)=\frac{1}{2 \pi} \int_{-\infty}^{\infty} \int_{-\infty}^{\infty} A(t ; \theta ; \tau) \Phi_{\mathrm{opt}}(t ; \theta ; \tau) e^{-j \theta \tau-j f t} d \theta d \tau,
$$

where $\Phi_{\text {opt }}(t ; \theta ; \tau)$ is the optimal kernel function; $A(t ; \theta ; \tau)$ is the short-time ambiguity function; $\theta$ is the angle function in polar coordinates; $\tau$ is the time interval; and $f$ is the frequency.

The definition of the short-time ambiguity function $A(t ; \theta ; \tau)$ is as follows:

$$
\begin{aligned}
A(t ; \theta ; \tau)= & \int_{-\infty}^{\infty} h\left(u-\frac{\tau}{2}\right) w\left(u-t-\frac{\tau}{2}\right) h\left(u+\frac{\tau}{2}\right) \\
& \cdot f\left(u-t+\frac{\tau}{2}\right) e^{j \theta u} d u,
\end{aligned}
$$

where $w(u)$ is the symmetric window function and $t$ is the center of $w(u)$.

Provided that $|u|>T, w(u)=0$, the kernel function of the signal just can be calculated out in the range of $[t-T, t+T]$, while the short-time ambiguity function can express the details accurately. The value of $\theta_{\text {opt }}(t ; \theta ; \tau)$ can be readily calculated out with the help of the short-time ambiguity function. As $A(t ; \theta ; \tau)$ changes with time, $\theta_{\text {opt }}(t ; \theta ; \tau)$ will be alterable too. $\theta_{\text {opt }}(t ; \theta ; \tau)$ can be obtained by solving the following optimization function:

$$
\frac{\max }{\Phi} \int_{0}^{2 \pi} \int_{0}^{+\infty}|A(t ; t ; \varphi) \Phi(t ; t ; \varphi)|^{2} r d r d \varphi
$$

The constraint conditions are shown as follows:

$$
\left\{\begin{array}{l}
\Phi(t ; t ; \varphi)=\exp \left(-\frac{r^{2}}{2 \sigma^{2}(\varphi)}\right), \\
\frac{1}{2 \pi} \int_{0}^{2 \pi} \int_{0}^{+\infty}|\Phi(t ; t ; \varphi)|^{2} r d r d \varphi=\frac{1}{2 \pi} \int_{0}^{2 \pi} \sigma^{2}(\varphi) d \varphi \leq \alpha,
\end{array}\right.
$$

where $\sigma(\varphi)$ is the extension function; $\varphi$ is the angle between the radial and horizontal direction, $\varphi=\arctan (\tau / \theta)$ and $r=\left(\theta^{2}+\tau^{2}\right)^{1 / 2}$; and $\alpha$ is the energy volume of radial gaussian kernel. Some self-components of the kernel functions will be filtered out with too small $\alpha$, while the cross components cannot be effectively removed with overlarge $\alpha$, and the rational value of $\alpha$ is $[1,5]$ [34].

4.1.3. Calculation of SWE. When the seismic signals are decompose, the number of layers should be determined by the specific signals and the frequency bands of the blasting vibration meters. Assume that the signal is decomposed to the layer $n$, namely, there are total $n+1$ sets of frequency bands. The signals with random frequency bands are analysed by the AOK time-frequency analysis method, and $P(t, f)$ in certain moment and certain frequency can be obtained. Thus, the SWE can be solved by the following equation:

$$
E_{n}=\int_{-\infty}^{\infty} \int_{-\infty}^{\infty} P(t, f) d t d f=\sum_{t=1}^{n} \sum_{f=1}^{m} e(t, f)
$$

where $E_{n}$ is the SWE corresponding to the $n$th frequency band.

The proportion of SWE corresponding to each band can be expressed as $r_{n}$, as follows:

$$
r_{n}=\frac{E_{n}}{E} \times 100 \%
$$

4.2. Characteristics of SWE. In terms of the sampling features of the measured seismic wave, the sampling interval is set at 4000 sps. According to the Nyquist theorem, the Nyquist frequency of the measured signal is $2000 \mathrm{~Hz}$. The measured signals are decomposed into 8 layers with the help of wavelet transform, and the bandwidth of the eighth lowfrequency wavelets (a8) is $0 \sim 7.8125 \mathrm{~Hz}$. The bandwidth of each band is depicted in Table 5 .

When adopting db8 wavelet base function to decompose and reconstruct the measured seismic wave, the relative error between the reconstructed signal and the measured signal is the minimal one. Thus, db8 wavelet base function is selected to decompose and reconstruct all the measured signals in this study, and the relative error is 
TABle 5: Bandwidth distribution of measured seismic wave.

\begin{tabular}{lccccccccc}
\hline Band & $\mathrm{a} 8$ & $\mathrm{~d} 8$ & $\mathrm{~d} 7$ & $\mathrm{~d} 6$ & $\mathrm{~d} 5$ & $\mathrm{~d} 4$ & $\mathrm{~d} 3$ & $\mathrm{~d} 2$ & $\mathrm{~d} 1$ \\
\hline Bandwidth $(\mathrm{Hz})$ & $0 \sim 7.8125$ & $7.8125 \sim 15.625$ & $15.625 \sim 31.25$ & $31.25 \sim 62.5$ & $62.5 \sim 125$ & $125 \sim 250$ & $250 \sim 500$ & $500 \sim 1000$ & $1000 \sim 2000$ \\
\hline
\end{tabular}
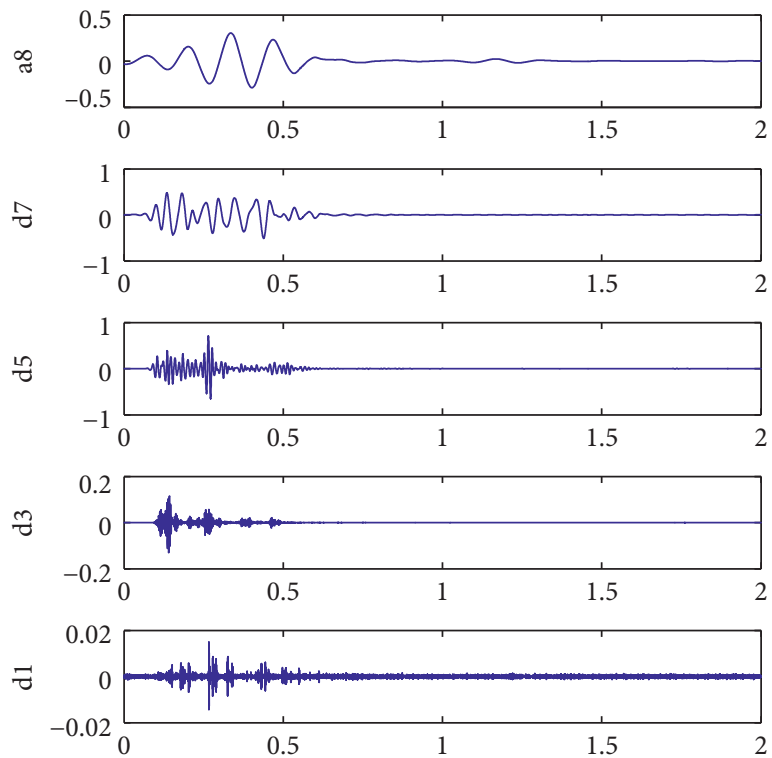

FIgURE 4: Reconstructed signal of each band in vertical direction.

about $1.02 \times 10^{-11} \sim 2.07 \times 10^{-11}$, which can fully meet the requirements of the practical project. The reconstructed signal of each band in vertical direction is shown in Figure 4.

The time-frequency characteristics and energy density of each reconstructed signal can be obtained with the help of AOK time-frequency analysis, as shown in Figure 5. As depicted in the time-frequency spectrum, the major centralized area can be clearly distinguished. The centralized time is about $0.1 \mathrm{~s}$, and the frequency mainly ranges from 0 to $125 \mathrm{~Hz}$. Comparing all the time-frequency characteristics and energy density blow, it is found that the energies of low frequency bands ( $\mathrm{d} 5 \sim \mathrm{d} 8$ and $\mathrm{a} 8$ ) are huge, while those of high-frequency bands $(\mathrm{d} 1 \sim \mathrm{d} 4)$ are tiny. The durations of $\mathrm{d} 1$ and $\mathrm{d} 2$ occupy more than half of time, and the energies are extremely low, which denotes that the bands are mainly signal noise in the whole process of blasting.

According to equations (13) (16), the energies for reconstructed signals in three directions, the total energy, and the energy proportions can be calculated out (Table 6). The energies of reconstructed signals in each band are depicted in Figure 6.

As seen from Table 5 and Figure 6, the energy proportions of seismic wave in the bands of $\mathrm{d} 5 \sim \mathrm{d} 8$ and a 8 are totally $85 \%$, while energies in other bands are extremely low, which indicates that the dominant frequency ranges from 0 to $125 \mathrm{~Hz}$. As the high-frequency bands of $\mathrm{d} 1$ and $\mathrm{d} 2$ are mainly noise signals, which can be left out when studying SWE. The bands of $\mathrm{d} 3$ and $\mathrm{d} 4$ are in the range of $125 \sim 500 \mathrm{~Hz}$, which are higher than the natural vibration frequencies of nearby structures.
The frequency bands in the range of $0 \sim 125 \mathrm{~Hz}$ are the key to study SWE. However, there are significant differences in the SWE of different directions. The value of horizontal tangential energy is the maximum, and horizontal radial energy is the minimum. The range of dominant frequency of horizontal tangential, horizontal radial, and vertical direction are, respectively, $0 \sim 31.25 \mathrm{~Hz}, 15.625 \sim 125 \mathrm{~Hz}$, and $7.8125 \sim 62.5 \mathrm{~Hz}$.

4.3. Attenuation Law of SWE. 5 sets of monitoring data with different distances from the blast-face to the monitoring points $(65 \mathrm{~m}, 75 \mathrm{~m}, 85 \mathrm{~m}, 105 \mathrm{~m}$, and $125 \mathrm{~m})$ in the same blasting are selected to analyse the characteristics of SWE. The energy components of the 5 monitoring points in 3 directions, horizontal tangential, horizontal radial, and vertical direction, as well as the total energy are calculated, as depicted in Table 7. The attenuation laws of energy components along with distance can be obtained from Figure 7.

As seen from Table 6 and Figure 7, the attenuation laws of SWE along with distance in each direction are roughly the same. At the same distance from the measured point to the blast-face, horizontal tangential energy is the minimal one and attenuates rapidly, while horizontal radial energy is the largest one and changes relatively slowly. All the seismic wave energies present typical forms of exponential decay, that is to say, when near the blast-face, the energies attenuate rapidly, and with the increase of distance, the attenuation rates are obviously reduced. When it comes to zones far away from the blast-face, the energies attenuate extremely slowly. Fit the total energy of seismic wave with the help of 


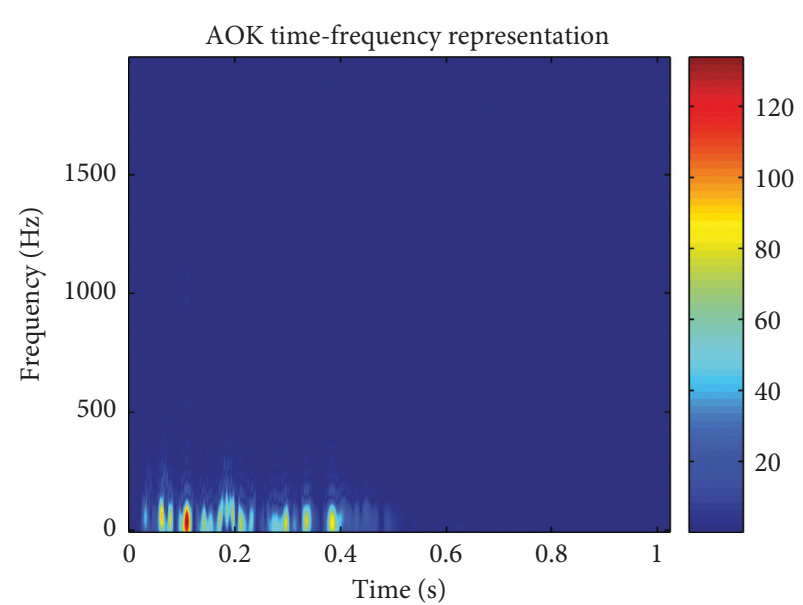

(a)

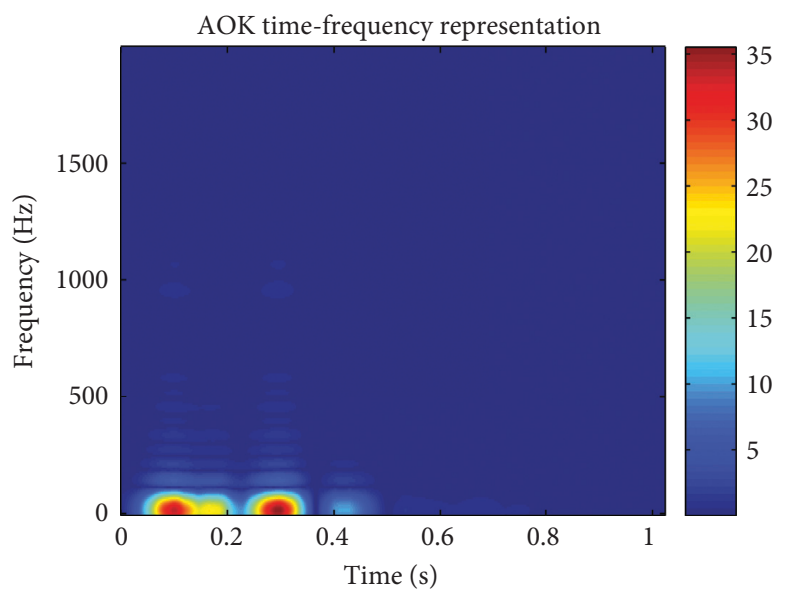

(c)

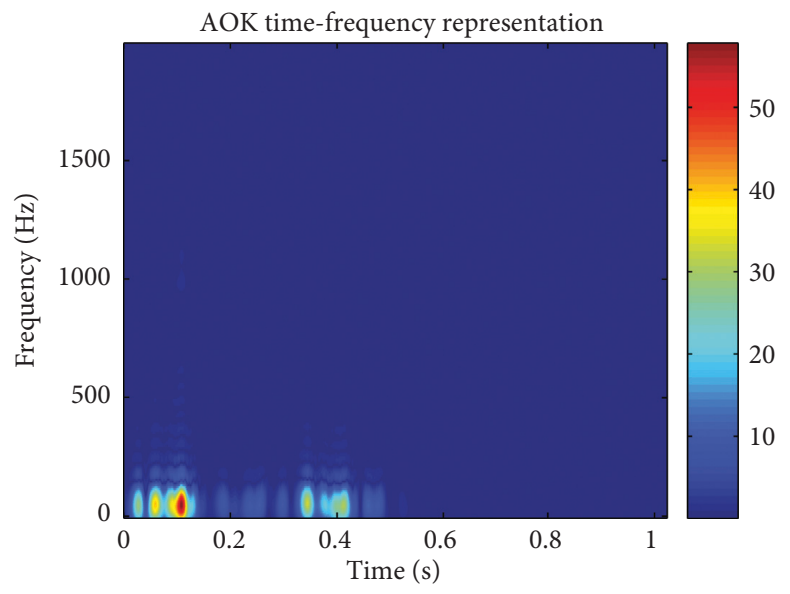

(e)

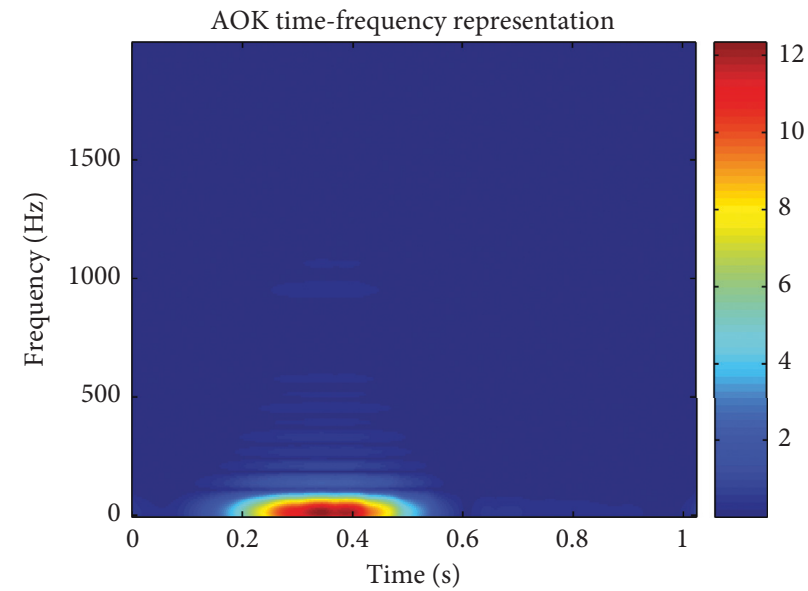

(b)

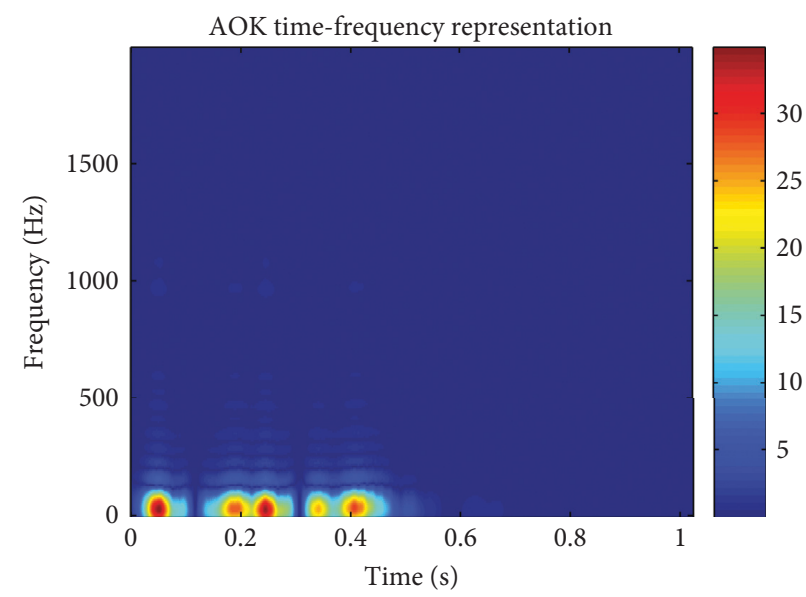

(d)

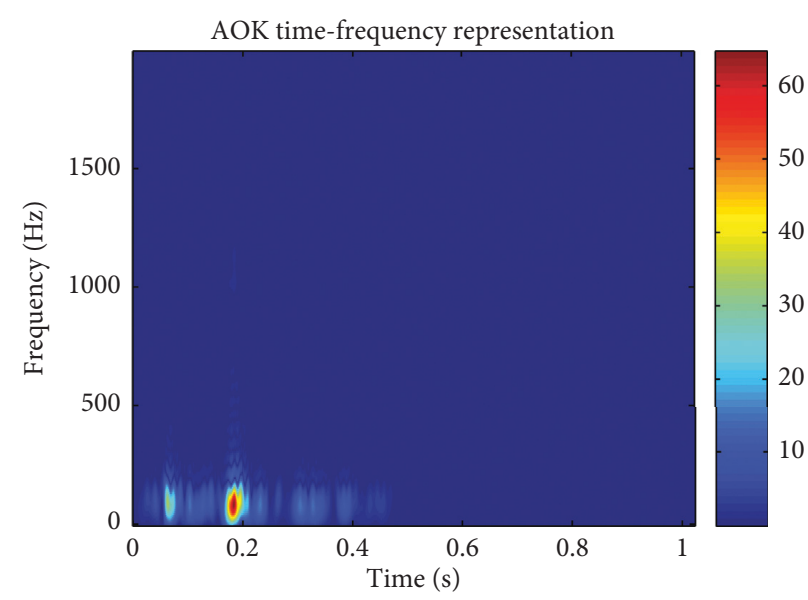

(f)

Figure 5: Continued. 


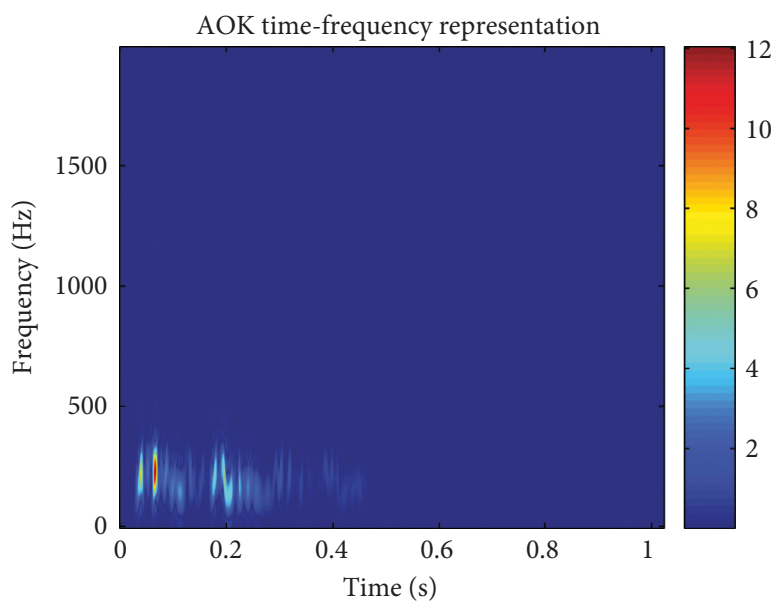

(g)

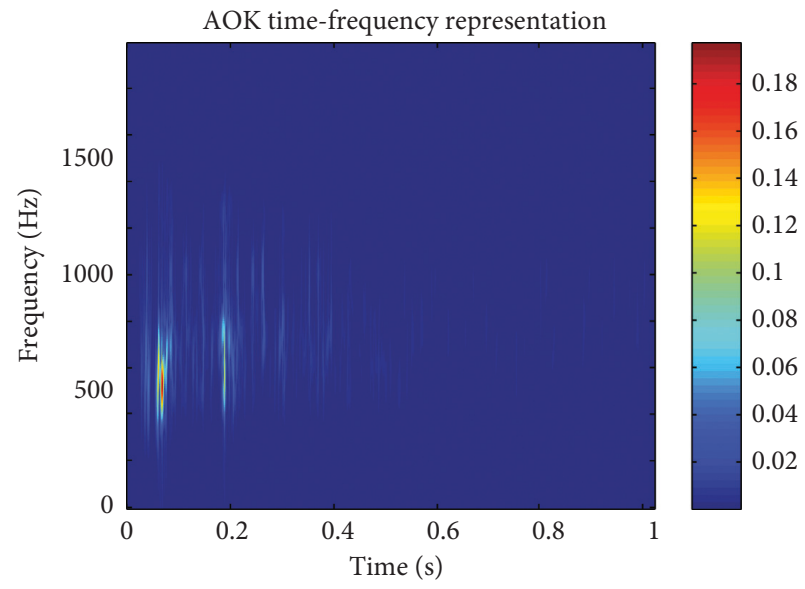

(i)

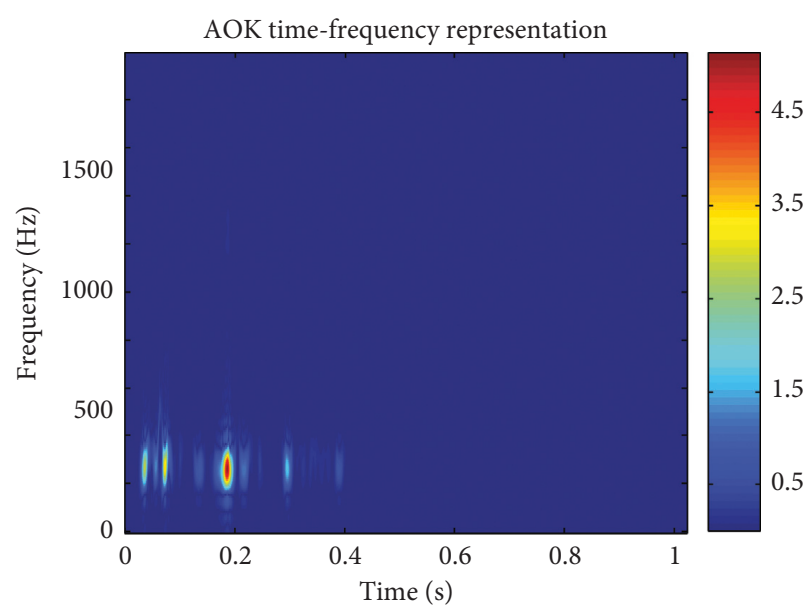

(h)

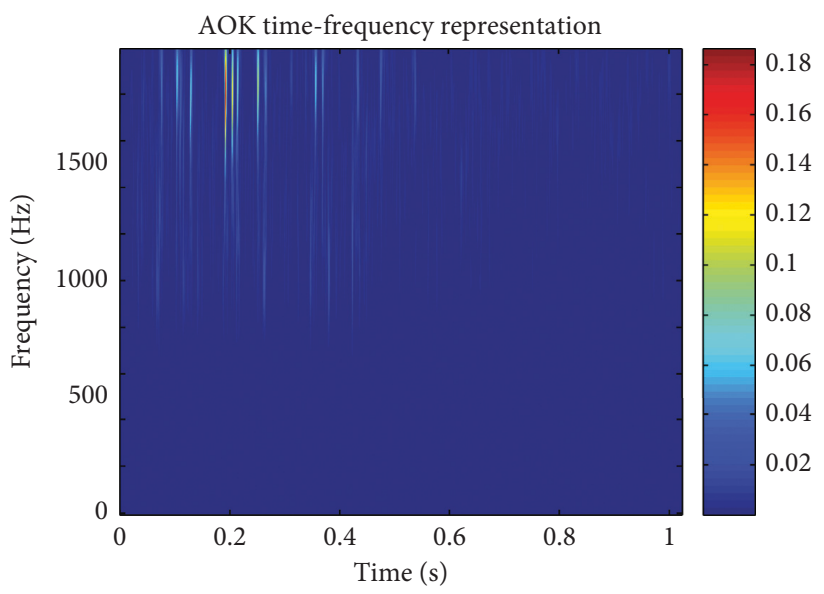

(j)

Figure 5: Time-frequency spectrum for each reconstructed signal: (a) as1, (b) a8, (c) d8, (d) d7, (e) d6, (f) d5, (g) d4, (h) d3, (i) d2, and (j) d1.

TABLE 6: Energy components, total energy, and energy proportions of reconstructed signals.

\begin{tabular}{|c|c|c|c|c|c|c|}
\hline \multirow{2}{*}{ Frequency band } & \multicolumn{2}{|c|}{ Horizontal tangential } & \multicolumn{2}{|c|}{ Horizontal radial } & \multicolumn{2}{|c|}{ Vertical direction } \\
\hline & $E_{n}\left(\mathrm{~cm}^{2} / \mathrm{s}^{2}\right)$ & $P_{n}(\%)$ & $E_{n}\left(\mathrm{~cm}^{2} / \mathrm{s}^{2}\right)$ & $P_{n}(\%)$ & $E_{n}\left(\mathrm{~cm}^{2} / \mathrm{s}^{2}\right)$ & $P_{n}(\%)$ \\
\hline a8 & 407.193 & 40.275 & 1.9167 & 1.566 & 9.520 & 6.333 \\
\hline $\mathrm{d} 8$ & 358.930 & 35.501 & 5.555 & 4.539 & 38.802 & 25.814 \\
\hline d7 & 146.421 & 14.482 & 31.778 & 25.964 & 41.292 & 27.471 \\
\hline d6 & 57.142 & 5.652 & 38.028 & 31.070 & 36.239 & 24.108 \\
\hline d5 & 36.035 & 3.564 & 31.078 & 25.392 & 22.797 & 15.166 \\
\hline $\mathrm{d} 4$ & 4.244 & 0.420 & 8.192 & 6.693 & 1.340 & 0.892 \\
\hline d3 & 0.788 & 0.0780 & 3.889 & 3.178 & 0.321 & 0.213 \\
\hline $\mathrm{d} 2$ & 0.176 & 0.0170 & 1.536 & 1.255 & 0.00242 & 0.00147 \\
\hline $\mathrm{d} 1$ & 0.111 & 0.0110 & 0.419 & 0.343 & 0.00251 & 0.00153 \\
\hline$E\left(\mathrm{~cm}^{2} / \mathrm{s}^{2}\right)$ & \multirow{2}{*}{\multicolumn{2}{|c|}{1011.039}} & \multirow{2}{*}{\multicolumn{2}{|c|}{$\begin{array}{l}122.392 \\
1283.748\end{array}$}} & \multirow{2}{*}{\multicolumn{2}{|c|}{150.317}} \\
\hline$E_{t}\left(\mathrm{~cm}^{2} / \mathrm{s}^{2}\right)$ & & & & & & \\
\hline
\end{tabular}

exponential function, and the attenuation formula is shown in the following equation:

$$
E_{t}=1.651 \times 10^{17} R^{-7.783}, \quad r^{2}=0.994
$$

Five major bands, with frequency of $0 \sim 125 \mathrm{~Hz}$, are employed to study the attenuation law of SWE. The attenuation laws of the total energy and energy pro portion of each band are, respectively, depicted in Figures 8 and 9.

As seen from the above figures, the total SWE of each band all experiences exponential attenuation with the increase of distance. Among which, the total energies of the bands a 8 and $\mathrm{d} 8$ present the slowest attenuation, 


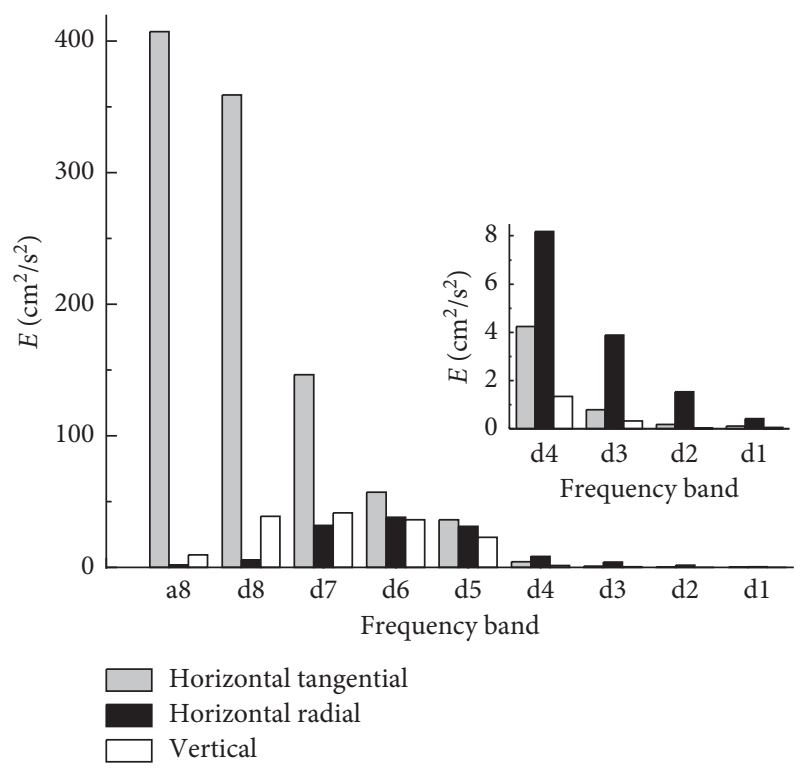

FIGURE 6: Energies of reconstructed signals in each band.

TABLE 7: SWE in different distances from the blast-face to the monitoring points.

\begin{tabular}{|c|c|c|c|c|}
\hline \multirow[b]{2}{*}{ Distance from the measured point to the blast-face } & \multicolumn{3}{|c|}{ Energy components $E\left(\mathrm{~cm}^{2} / \mathrm{s}^{2}\right)$} & \multirow[b]{2}{*}{ Total energy $E_{t}\left(\mathrm{~cm}^{2} / \mathrm{s}^{2}\right)$} \\
\hline & $\begin{array}{c}\text { Horizontal } \\
\text { tangential }\end{array}$ & $\begin{array}{c}\text { Horizontal } \\
\text { radial }\end{array}$ & $\begin{array}{c}\text { Vertical } \\
\text { direction }\end{array}$ & \\
\hline 65 & 1011.039 & 122.392 & 150.317 & 1283.748 \\
\hline 75 & 302.307 & 50.321 & 58.712 & 411.34 \\
\hline 85 & 115.844 & 25.273 & 27.135 & 168.252 \\
\hline 105 & 19.398 & 8.5198 & 9.275 & 37.192 \\
\hline 125 & 10.485 & 7.047 & 6.425 & 23.957 \\
\hline
\end{tabular}

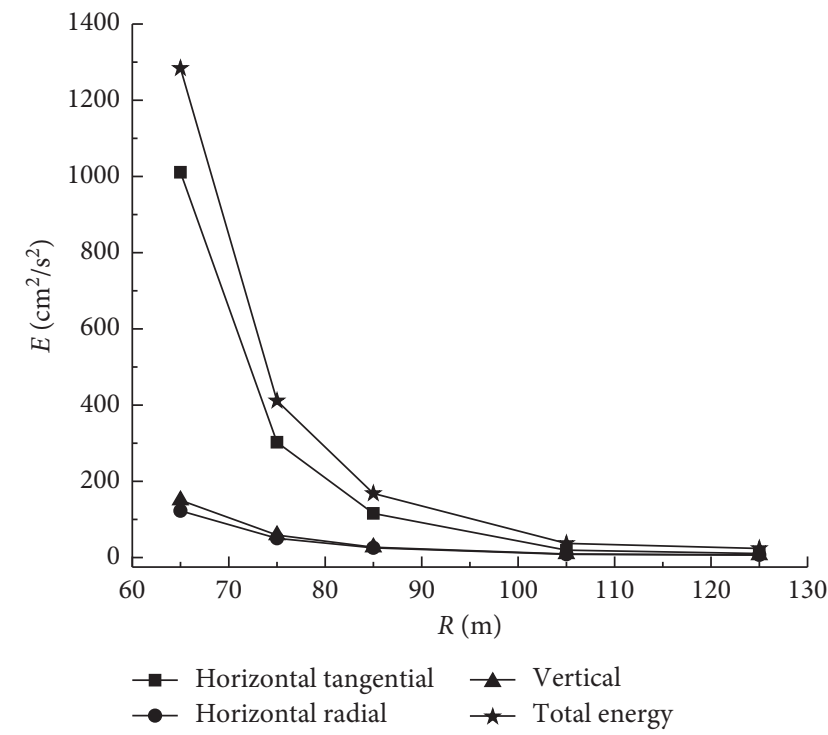

Figure 7: Attenuation laws of energy components along with distance.

which indicates that the lower the frequency is, the more gentle the energy attenuation is. With the increase of distance, the energy proportions of the bands $\mathrm{d} 5 \sim \mathrm{d} 7$

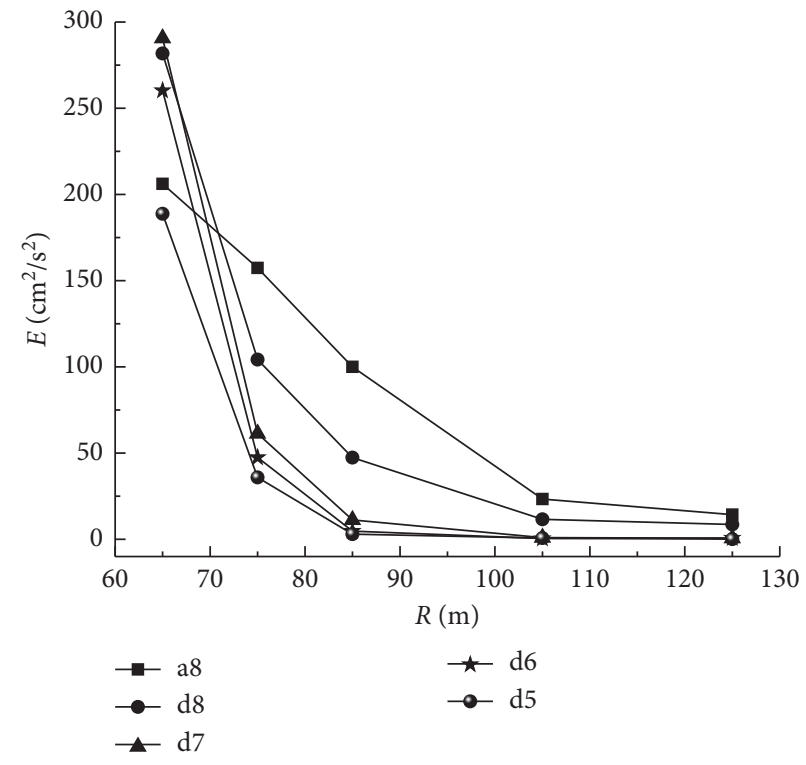

Figure 8: Attenuation laws of the total energies along with distance.

constantly decrease, while those of the bands a 8 and $\mathrm{d} 8$ increase gradually. As the distance from the measured point to the blast-face is $125 \mathrm{~m}$, the total energy 


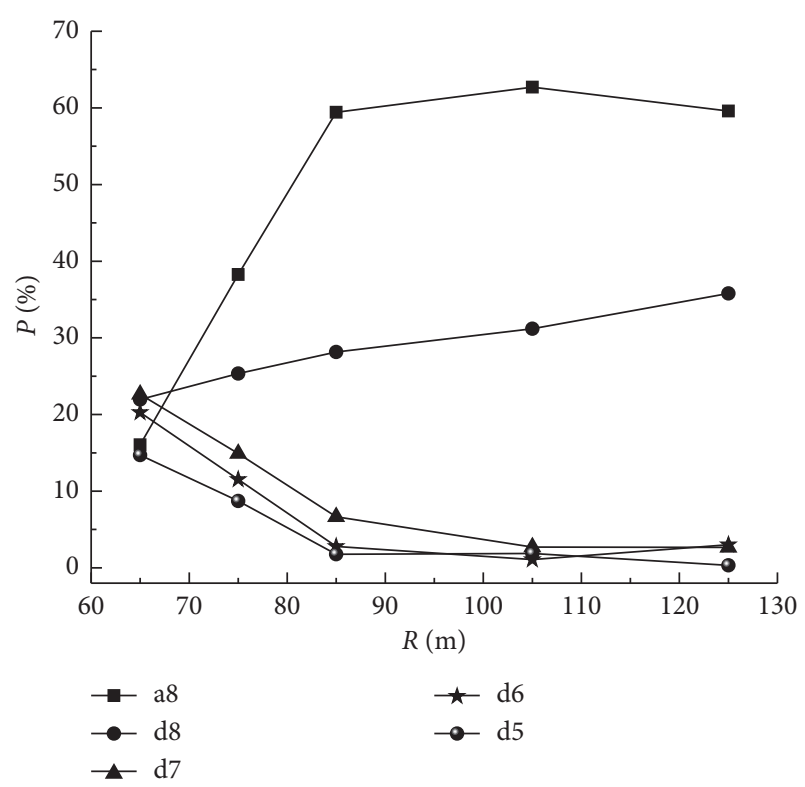

FIgURE 9: Attenuation laws of the energy proportions along with distance.

proportion of the bands in the frequency of $0 \sim 12.625 \mathrm{~Hz}$ is up to $95.393 \%$.

\section{Prediction of SWE and Discussion}

Thirty groups of measured signals are employed to analyse the characteristics of SWE, and the total energy of each band $E_{t}$ is fitted by equation (12). And, the prediction formulas are adopted to fit the measured PPVs. The results are shown in Table 8.

The relationship between the measured total energy $E_{\mathrm{t}}$ and the predicted one is depicted in Figure 10. Figures 11-15 demonstrate the deviations of the measured PPVs when compared with the predicted PPVs fitted by USBM, Langefors-Kihlstrom, Bureau of Indian Standard, Sadaovsk formula, and CCTS. To check the capacity performance of the prediction models, values of mean absolute percent error (MAPE) are solved via the following equation:

$$
\text { MAPE }=\left(\frac{1}{n} \sum_{i=1}^{n} \frac{\left|y-y^{\prime}\right|}{y}\right) \times 100,
$$

where $y$ and $y^{\prime}$ are the measured and predicted values and $n$ is the total number of the data. When the MAPE value is zero, the model's performance is prefect.

The performance indices of all the mentioned models are shown in Table 9. In the prediction of PPVs, the MAPE values obtained by USBM, Langefors-Kihlstrom, Bureau of Indian Standard, Sadaovsk formula, and CCTS $[4-7,9]$ are, respectively, $18.459 \%, 27.426 \%, 27.435 \%$, $15.897 \%$, and $13.566 \%$, which indicates that the accuracy of CCTS in predicting PPV is better than that of other formulas.

The performance indices $R^{2}$ and MAPE of the energy prediction formula deduced in this study are, respectively,
TABLE 8: Fitting results of different prediction formulas.

\begin{tabular}{lcccc}
\hline \multirow{2}{*}{ Prediction formula } & \multicolumn{4}{c}{ Parameters } \\
& $k$ & $\alpha$ & $\beta$ & $R^{2}$ \\
\hline USBM & 4.870 & 1.077 & - & 0.828 \\
Langefors-Kihlstrom & 0.413 & 2.413 & - & 0.692 \\
Bureau of Indian Standard & 0.413 & 1.207 & - & 0.702 \\
Sadaovsk formula & 123.016 & 1.467 & - & 0.842 \\
CCTS & 107.06 & 1.572 & -0.223 & 0.875 \\
Equation (12) & 6.148 & 5.951 & 0.211 & 0.911 \\
\hline
\end{tabular}

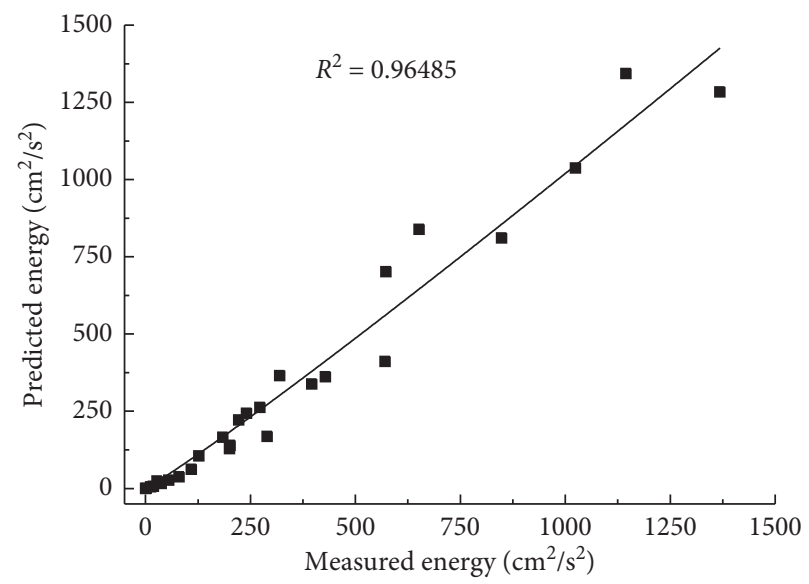

FIGURE 10: Measured energy against predicted energy fitted by energy prediction formula.

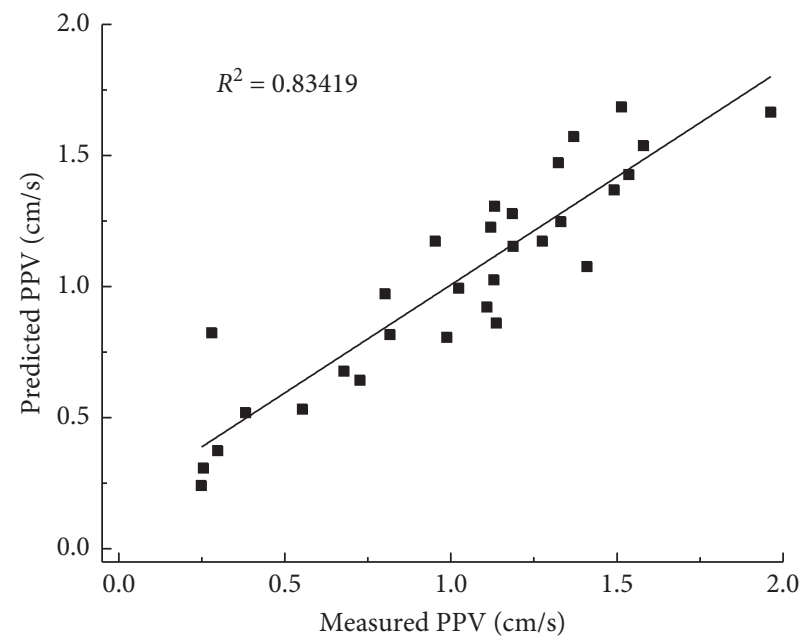

FIgURE 11: Measured PPVs against predicted PPVs fitted by USBM.

0.96485 and $11.154 \%$, which are superior to the results of other formulas. That is to say, the energy prediction formula possesses excellent performance capacity and favorable prediction accuracy. It can be concluded that adopting SWE as the judgment standard of seismic intensity and fitting the energy with the help of the prediction formula in this study can achieve more accurate prediction results, which provides solid basis for the safety control to the harmful effects of seismic waves. 


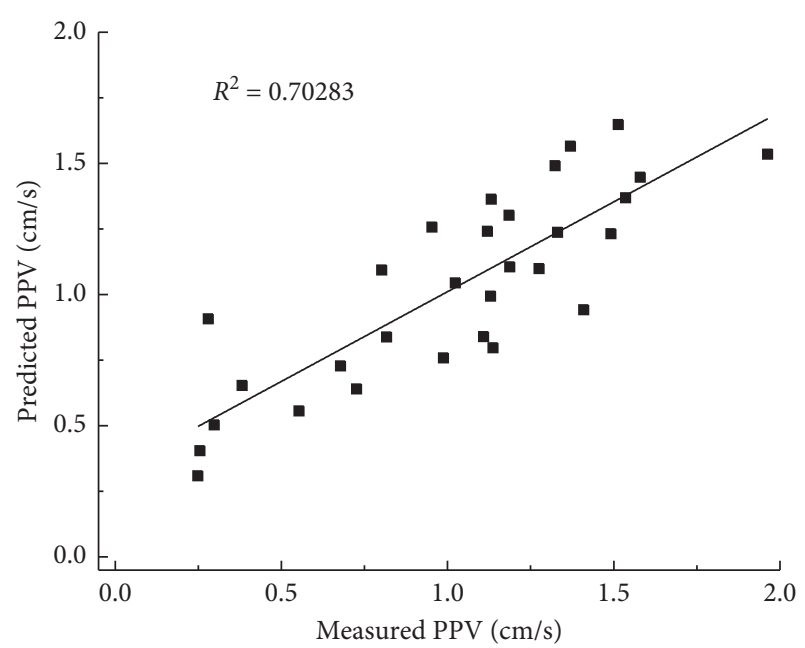

Figure 12: Measured PPVs against predicted PPVs fitted by Langefors-Kihlstrom.

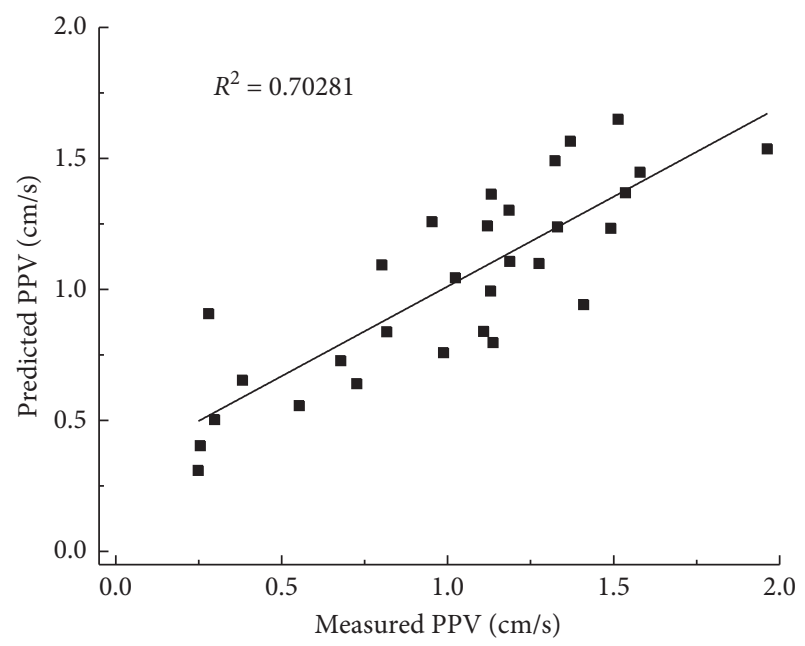

Figure 13: Measured PPVs against predicted PPVs fitted by the Bureau of Indian Standard.

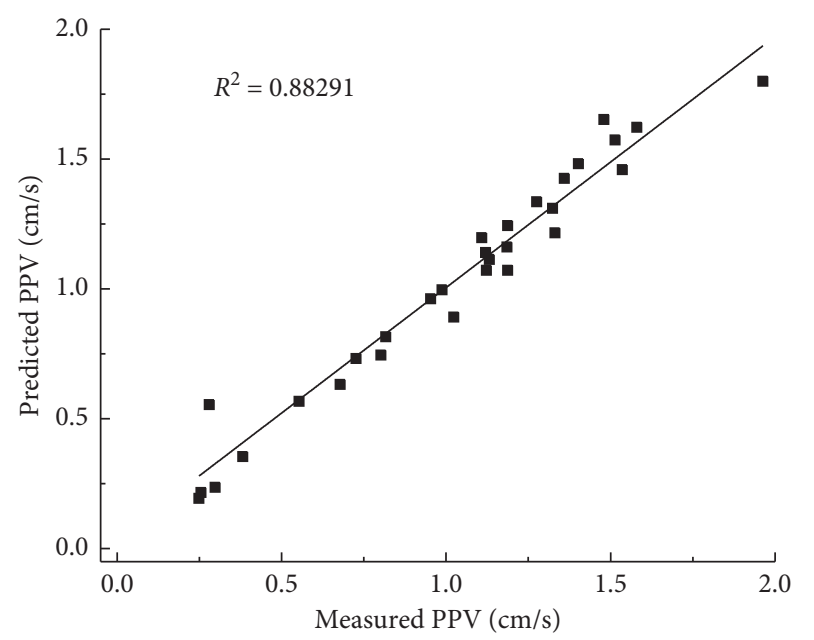

Figure 14: Measured PPVs against predicted PPVs fitted by Sadaovsk formula.

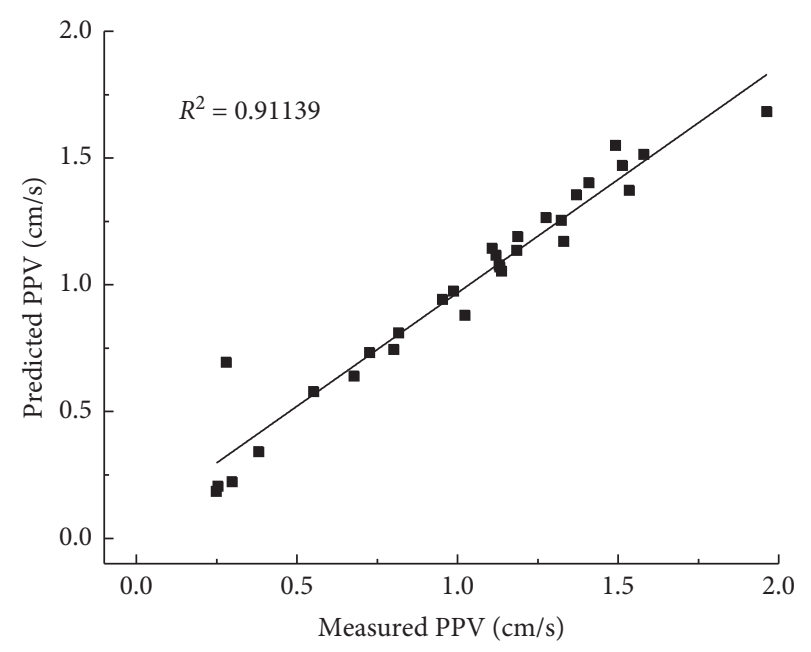

FIgURE 15: Measured PPVs against predicted PPVs fitted by CCTS.

TABle 9: Performance indices of all prediction models.

\begin{tabular}{lcc}
\hline Predictive model & $R^{2}$ & MAPE (\%) \\
\hline Energy prediction formula & 0.96485 & 11.154 \\
USBM [4] & 0.83419 & 18.459 \\
Langefors and Kihlstrom [5] & 0.70283 & 27.426 \\
Bureau of Indian Standard [6] & 0.70281 & 27.435 \\
Sadaovsk formula [7] & 0.88291 & 15.897 \\
CCTS [9] & 0.91139 & 13.566 \\
\hline
\end{tabular}

\section{Conclusion}

In the blasting engineering, PPV has been the major index to describe the intensity of seismic waves. Nevertheless, many countries' safety criterion ignored the effects of duration time and vibration frequency. The paper regards the seismic wave energy as the index to quantify seismic intensity, puts forward the prediction formula of seismic wave energy, and obtains the distribution characteristics and attenuation law of seismic wave energy. Conclusions can be drawn as follows:

(1) The energy proportions of seismic wave induced by underwater drilling and blasting in the bands of $\mathrm{d} 5 \sim \mathrm{d} 8$ and a 8 are totally $85 \%$, while energies in highfrequency bands are extremely low. The range of dominant frequency of horizontal tangential, horizontal radial, and vertical direction are, respectively, $0 \sim 31.25 \mathrm{~Hz}, 15.625 \sim 125 \mathrm{~Hz}$, and $7.8125 \sim 62.5 \mathrm{~Hz}$.

(2) All the seismic wave energies present typical forms of exponential decay, that is to say, when near the blastface, the energies attenuate rapidly, and with the increase of distance, the attenuation rates are obviously reduced. When it comes to zones far away from the blast-face, the energies attenuate extremely slowly.

(3) Comparing with other prediction formulas of PPV, adopting seismic wave energy as the judgment standard of seismic intensity and fitting the energy 
with the help of the prediction formula in this study can achieve more accurate prediction results, which provides solid basis for the safety control to the harmful effects of seismic waves.

\section{Data Availability}

All data included in this study are available upon request by contacting the corresponding author.

\section{Conflicts of Interest}

The authors declare that there are no conflicts of interest regarding the publication of this paper.

\section{Acknowledgments}

This work was supported by the Chinese National Natural Science Foundation (grant no. 41672260) and Hunan University of Science and Technology Doctoral Research Start-up Foundation (grant no. E51884).

\section{References}

[1] H. Ak and A. Konuk, "The effect of discontinuity frequency on ground vibrations produced from bench blasting: a case study," Soil Dynamics and Earthquake Engineering, vol. 28, no. 9, pp. 686-694, 2008.

[2] M. Monjezi, A. Bahrami, and A. Yazdian, "Simultaneous prediction of fragmentation and flyrock in blasting operation using artificial neural networks," International Journal of Rock Mechanics and Mining Science, vol. 47, no. 3, pp. 476-480, 2010.

[3] R. Ghoshal and N. Mitra, "Underwater explosion induced shock loading of structures: influence of water depth, salinity and temperature," Ocean Engineering, vol. 126, no. 1, pp. 22-28, 2016.

[4] W. I. Duvall and D. E. Fogelson, Review of Criteria for Estimating Damage to Residences from Blasting Vibration, USBM, Washington, DC, USA, 1962.

[5] U. Langefors and B. Kihlstrom, The Modern Technique of Rock Blasting, Wiley, New York, NY, USA, 1963.

[6] Bureau of Indian Standard, Criteria for Safety and Design of Structures Subjected to Underground Blast, ISI Bulletin IS-6922, Bureau of Indian Standard, New Delhi, India, 1973.

[7] Sadaovsk, Earthquake Forecasting, Seismological Press, Beijing, China, 1996.

[8] H. Tang and H. B. Li, "Study of blasting vibration formula of reflecting amplification effect on elevation," Rock and Soil Mechanics, vol. 32, no. 3, pp. 820-824, 2011.

[9] National Development and Reform Commission, DL/T53892007, Construction Technical Specifications on Rock-Foundation, Excavating Engineering of Hydraulic Structures, National Development and Reform Commission, Beijing, China, 2007.

[10] Y.-X. Peng, L. Wu, Y. Su, H.-Y. Li, and C.-J. Li, "Study on the fitting model of underwater blasting vibration attenuation considering the effect of elevation," Journal of Vibration and Shock, vol. 35, no. 13, pp. 174-178, 2016.

[11] Y. Peng, L. Wu, C. Chen, B. Zhu, and Q. Jia, "Study on the robust regression of the prediction of vibration velocity in underwater drilling and blasting," Arabian Journal for Science and Engineering, vol. 43, no. 10, pp. 5541-5549, 2018.
[12] W. Gu, Z. Wang, J. Liu, J. Xu, X. Liu, and T. Cao, "Experimental study on the measurement of water bottom vibration induced by underwater drilling blasting," Shock and Vibration, vol. 2015, Article ID 496120, 8 pages, 2015.

[13] W. Gu, Z. Wang, J. Liu, J. Xu, X. Liu, and T. Cao, "Waterdepth-based prediction formula for the blasting vibration velocity of lighthouse caused by underwater drilling blasting," Shock and Vibration, vol. 2017, Article ID 7340845, 9 pages, 2017.

[14] J. H. Wen, X. P. Li, W. C. Zhang et al., "A study of parameter inversion of blasting vibration based on compositely genetic algorithm," Rock and Soil Mechanics, vol. 26, no. 1, pp. 160-162, 2005.

[15] X. Z. Shi, X. Chen, C. X. Shi, B. Liu, and X. Zhang, "Prediction model for blasting vibration peak speed based on GEP," Journal of Vibration and Shock, vol. 34, no. 10, pp. 95-99, 2015.

[16] M. Khandelwal and T. N. Singh, "Prediction of blast induced ground vibrations and frequency in opencast mine: a neural network approach," Journal of Sound and Vibration, vol. 289, no. 4-5, pp. 711-725, 2006.

[17] M. Khandelwal and T. N. Singh, "Evaluation of blast-induced ground vibration predictors," Soil Dynamics and Earthquake Engineering, vol. 27, no. 2, pp. 116-125, 2007.

[18] M. Khandelwal, "Blast-induced ground vibration prediction using support vector machine," Engineering with Computers, vol. 27, no. 3, pp. 193-200, 2011.

[19] Y. Q. Liu, H. B. Li, Q. T. Pei, and .W Zhang, "Prediction of peak particle velocity induced by underwater blasting based on the combination of grey relational analysis and genetic neural network," Rock and Soil Mechanics, vol. 34, no. 1, pp. 259-264, 2013.

[20] J. Yang, W. Lu, Q. Jiang, C. Yao, S. Jiang, and L. Tian, “A study on the vibration frequency of blasting excavation in highly stressed rock masses," Rock Mechanics and Rock Engineering, vol. 49, no. 7, pp. 2825-2843, 2016.

[21] J. Zhou, W. Lu, P. Yan, M. Chen, and G. Wang, "Frequencydependent attenuation of blasting vibration waves," Rock Mechanics and Rock Engineering, vol. 49, no. 10, pp. 40614072, 2016.

[22] D. W. Zhong, L. He, P. Cao, and K. Zhang, "Analysis of blasting vibration duration and optimizing of delayed time interval for millisecond blasting," Explosion and Shock Waves, vol. 36, no. 5, pp. 703-709, 2016.

[23] Y. X. Peng, L. Wu, Y. Su, and C. H. Chen, "Study on the effect of elevation on the prediction of underwater drill and blasting vibration frequency," Geosystem Engineering, vol. 19, no. 4, pp. 170-176, 2016.

[24] X. F. Lia, H. B. Li, and G. K. Zhang, "Damage assessment and blast vibrations controlling considering rock properties of underwater blasting," International Journal of Rock Mechanics and Mining Sciences, vol. 121, article 104045, 2019.

[25] J. A. Sanchidrián, P. Segarra, and L. M. López, "Energy components in rock blasting," International Journal of Rock Mechanics and Mining Sciences, vol. 44, no. 1, pp. 130-147, 2007.

[26] H.-T. Li, X.-G. Yang, D.-Q. Shu, W.-B. Lu, and X.-J. Gao, "Study on energy distribution characteristics of seismic waves induced by different forms of blasting resource," Journal of Sichuan University, vol. 42, no. 1, pp. 30-34, 2010.

[27] T.-H. Ling and X.-B. Li, "Analysis of energy distributions of millisecond blast vibration signals using the wavelet packet method," Chinese Journal of Rock Mechanics and Engineering, vol. 24, no. 7, pp. 1117-1122, 2005. 
[28] L. Yang, D. W. Zhong, L. He, and J.-F. Si, "Energy distribution characteristics research of underwater blasting vibration signal," Construction and Design for Engineering, vol. 1, pp. 125-127, 2013.

[29] M. Khandelwal and M. Saadat, "A dimensional analysis approach to study blast-induced ground vibration," Rock Mechanics and Rock Engineering, vol. 48, no. 2, pp. 727-735, 2015.

[30] L. Li, F. Wang, F. Shang, Y. Jia, C. Zhao, and D. Kong, "Energy spectrum analysis of blast waves based on an improved Hilbert-Huang transform," Shock Waves, vol. 27, no. 3, pp. 487-494, 2016.

[31] Y. Peng, L. Wu, Y. Su, B. Zhu, C. Chen, and B. Li, "Review of research on safety control of seismic wave and shock wave induced by underwater blasting," Geosystem Engineering, vol. 20, no. 3, pp. 172-179, 2016.

[32] S. G. Mallat, "Multiresolution approximation and wavelets," Transactions of the American Mathematical Society, vol. 315, no. 1, pp. 69-88, 1989.

[33] R. G. Baraniuk and D. L. Jones, A Signal-dependent TimeFrequency Representation: Optimal Kernel Design, IEEE Press, Piscataway, NJ, USA, 1993.

[34] X.-K. Wang, J.-H. Gao, and Y.-Y. He, "Time-frequency analysis based on time-frequency adaptive optimal-kernel," Systems Engineering and Electronics, vol. 32, no. 1, pp. 22-26, 2010. 


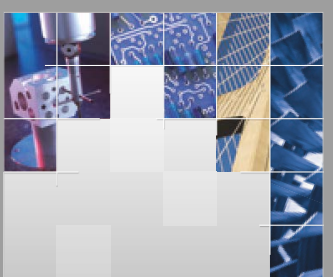

\section{Enfincering}
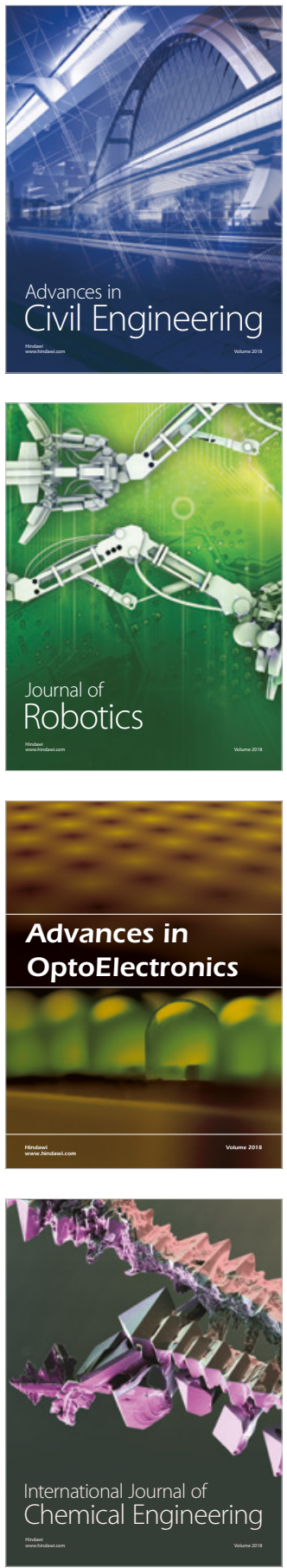

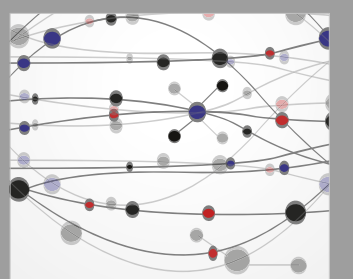

\section{Rotating \\ Machinery}

The Scientific World Journal

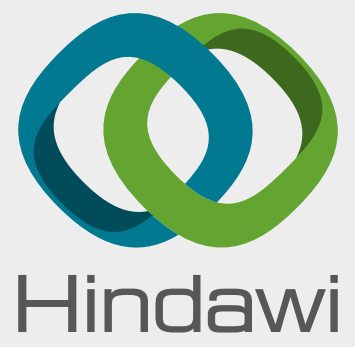

Submit your manuscripts at

www.hindawi.com
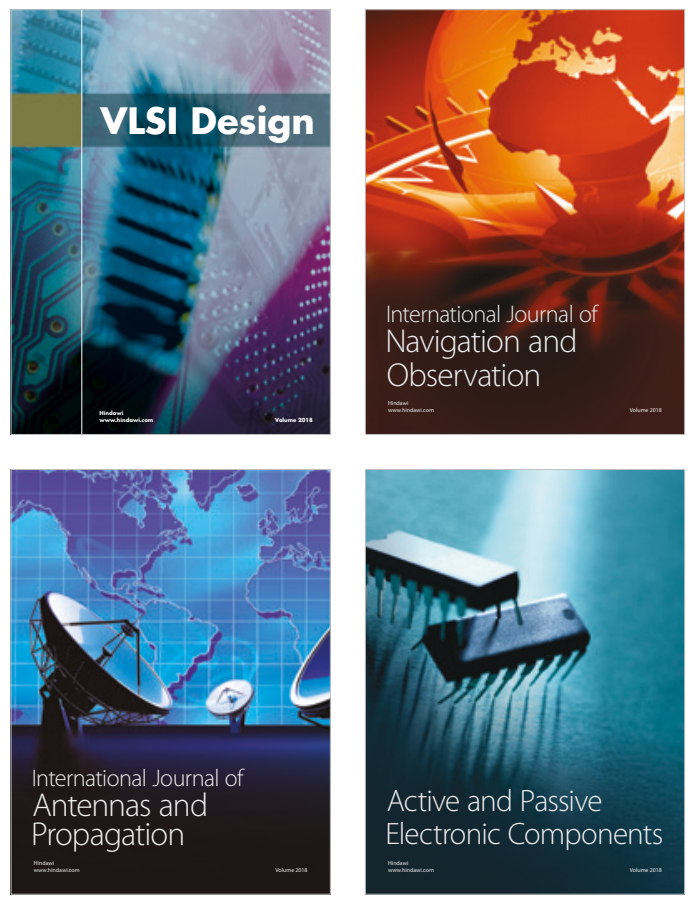
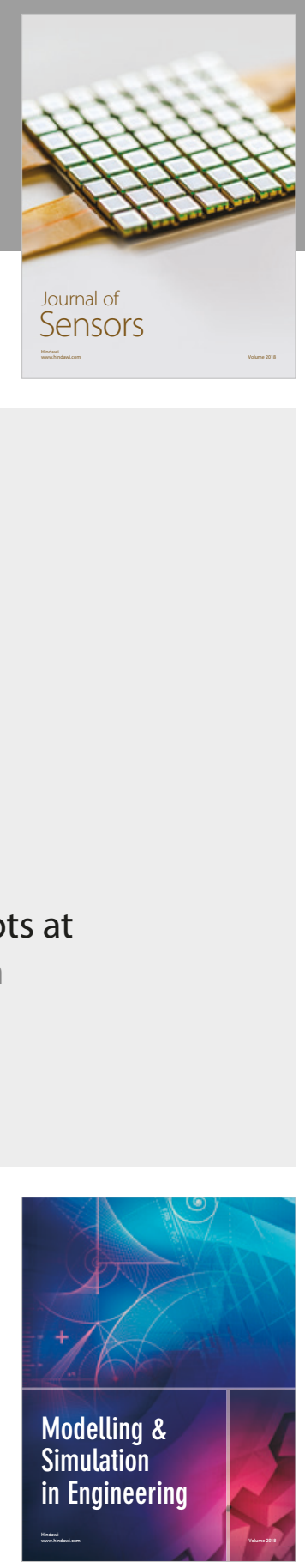

\section{Advances \\ Multimedia}
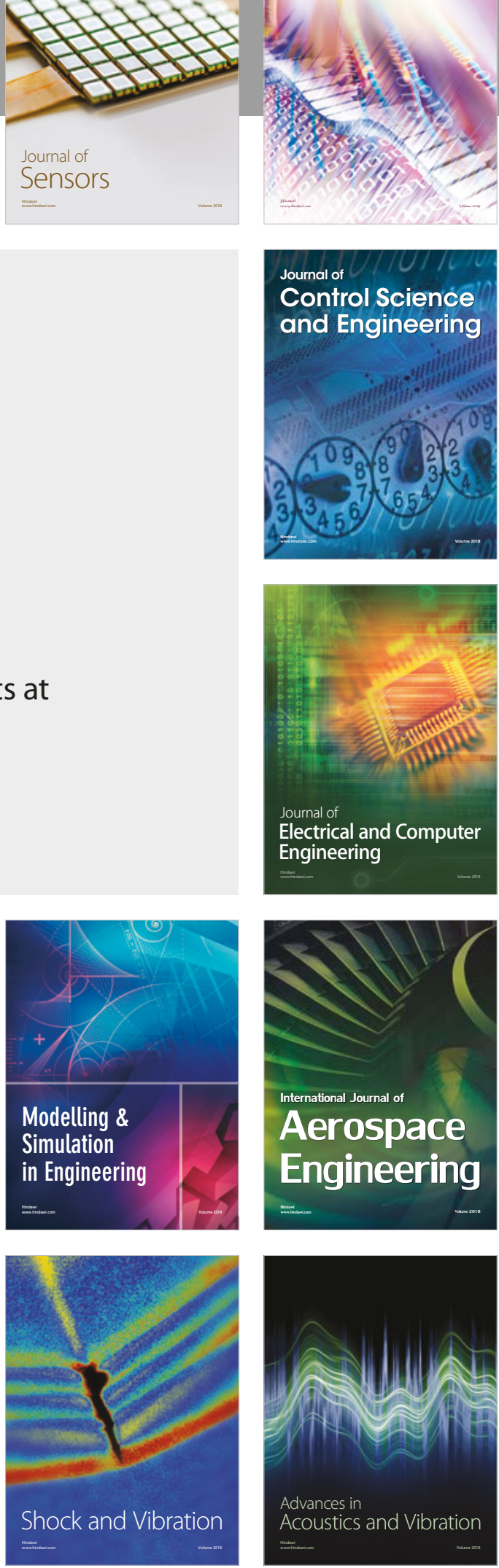